\title{
The Youth Self Report: Applicability and Validity Across Younger and Older Youths
}

\section{Citation}

Ebesutani, Chad, Adam Bernstein, Jonathan I. Martinez, Bruce F. Chorpita, and John R. Weisz. 2011. "The Youth Self Report: Applicability and Validity Across Younger and Older Youths." Journal of Clinical Child \& Adolescent Psychology 40 (2) (February 28): 338-346. doi:10.1080/15374416.2011.546041.

\section{Published Version}

doi: $10.1080 / 15374416.2011 .546041$

\section{Permanent link}

http://nrs.harvard.edu/urn-3:HUL.InstRepos:34257940

\section{Terms of Use}

This article was downloaded from Harvard University's DASH repository, and is made available under the terms and conditions applicable to Open Access Policy Articles, as set forth at http:// nrs.harvard.edu/urn-3:HUL.InstRepos:dash.current.terms-of-use\#OAP

\section{Share Your Story}

The Harvard community has made this article openly available.

Please share how this access benefits you. Submit a story.

\section{Accessibility}


RUNNING HEAD: YSR Scales

The Youth Self Report: Applicability and Validity Across Younger and Older Youths

\author{
Chad Ebesutani ${ }^{1}$ \\ Adam Bernstein ${ }^{1}$ \\ Jonathan I. Martinez ${ }^{1}$ \\ Bruce F. Chorpita ${ }^{1}$ \\ John R. Weisz ${ }^{2}$
}

\begin{abstract}
Psychology Department
University of California at Los Angeles, Los Angeles, California ${ }^{1}$

Psychology Department

Harvard University and Judge Baker Children's Center, Cambridge, Massachusett $s^{2}$
\end{abstract}




\section{Abstract}

The Youth Self Report (YSR) is a widely used measure of youth emotional and behavioral problems. Although the YSR was designed for youths ages 11-18, no studies have systematically evaluated whether youths under the age of 11 can make valid reports using the YSR broad-band, syndrome and DSM-oriented scales. This study thus examined the reliability and validity of the YSR scales scores for younger (ages 7-10; $\mathrm{n}=184$ ) and older (ages 11-14; $\mathrm{n}=147$ ) youths. Results demonstrated that younger youths were able to provide reliable reports on the YSR broad band (Internalizing, Externalizing) scales, though less so on the narrow band scales. Across all scales, the externalizing scales performed more favorably than the internalizing scales among both younger and older youth. Younger youths' DSM-oriented scales corresponded significantly with DSM diagnoses. Model fit of the narrow and broad band scales were also supported in both younger and older samples. These results provide initial support for administration of the YSR to younger youths.

Keywords: Youth Self Report, Younger Youths, DSMOriented Scales, Psychometric Properties 
The Youth Self Report (YSR; Achenbach \& Rescorla, 2001) is a prominent and widely used youth self-report measure for the assessment of emotional and behavioral problems among youth ages 11-18. Despite the wide usage of the YSR, a notable gap in the evidence base of the YSR is that few studies have assessed the reliability and validity of the YSR scales scores for youths under 11 years old. This is an important gap to fill given that some researchers have already begun administering the YSR to younger youths (below the intended age range of 11 - 18 years), such as in research settings (e.g., Kolko \& Kazdin, 1991; Yeh \& Weisz, 2001). Demonstrating more conclusive psychometric support of the YSR with younger youth samples would also provide the field with an empirically supported assessment tool with broadened applicability to enhance child assessment practices in both research and clinical contexts.

Previous studies have examined this question with other youth self-report measures, such as Muris and colleagues (2004) examining the psychometric properties of the Strength and Difficulties Questionnaire (SDQ) and finding general support for this measure for use among younger youths, ages 8-10 (originally intended for use with youths ages 11-17). A few studies have also evaluated the psychometric properties of YSR scales among youths under 11 years old. Kolko and Kazdin (1991) reported pilot testing the YSR among younger youth, and reported the 6- 
year olds were only "somewhat familiar" with the five items related to medical or physical conditions (p. 538). Kolko and Kazdin (1993) also administered the YSR to children ages 6-13, and found no differences between younger (6-9 years old) and older (10-13 years old) youths with respect to parent-child and teacher-child agreement on the YSR Internalizing, Externalizing and Total Problems scales. Yeh and Weisz (2001) also footnoted no differences between younger (ages 7-10) and older (ages 1118) youths' YSR syndrome scales' coefficient alpha values and test-retest reliability estimates.

Despite these initial explorations, no study has thoroughly or systematically examined the YSR scales across multiple psychometric domains with younger samples. Such studies are needed given that the YSR continues to be used with youth under 11 years old (e.g., McCarthy \& Weisz, 2002; Treutler, \& Epkins, 2003). Additional questions regarding the validity of younger youths' YSR reports remain unanswered (e.g., factor structure, concurrent validity), and thorough psychometric investigations specific to the YSR are needed before researchers and clinicians should begin widely using the YSR among younger samples. It remains unknown, for instance, whether younger youths can provide reliable and valid reports on both the YSR broad band and narrow band scales. The Present Study 
The current study sought to systematically examine the reliability and validity of the YSR broad and narrow band scale scores across younger (ages 7-10; n=184) and older (11-14; n=147) youths. We examined the psychometric properties of both younger and older youths' reports along the following dimensions: (a) factor structure, (b) scale reliability, (c) concurrent validity, and (d) parent-child agreement. Within each domain, we examined whether the test statistics of the younger group met general cut-off criteria for adequate reporting, as well as whether their test statistics were significantly different than the older group.

We hypothesized that the younger youths' reports would be associated with model fit indices in acceptable ranges, as previous studies have demonstrated that younger youths' reports on internalizing and externalizing measures were associated with supportive model fit indices (e.g., Muris et al., 2004). Regarding scale reliability, Yeh and Weisz (2001) previously examined the broad band and syndrome scales, reporting .76 as the average (internal consistency) alpha value among their younger youth sample, and no significant difference from the average alpha in their older group. We thus predicted that the Cronbach's alpha coefficients of the younger group's scales would not be significantly less than those of the older group. We could not make specific hypothesizes regarding the concurrent 
validity of younger youths' reports on the DSM-oriented scales given the mixed findings pertaining to their performance in the literature (cf. Ferdinand, 2008; Vreugdenhil et al., 2006). Based on Achenbach, McConaughy, and Howell's (1987) metaanalysis and Meyer and colleagues' (2001) review of parent-child agreement on psychosocial problems, we hypothesized that the older youth would evidence significant parent-child correlation coefficients in the range of .20 to .25. We further hypothesized that parent-child agreement for the younger group would show significantly smaller correlation coefficients than the older group given the generally lower parent-child agreement findings among younger youths (e.g., Edelbrock et al., 1986, Grills \& Ollendick, 2003).

Method

Participants

Youths in the present sample were drawn from 333 consecutively referred children and adolescents ages 7 to 14 who were seeking treatment in community clinic settings in Hawaii and Massachusetts for problems related to anxiety, depression and/or conduct problems. Criteria for selection into the present study included having available YSR data. All 333 consecutively referred youth had available YSR data. To help ensure that all YSRS represented valid reports with sufficient data, inclusion into the study also required each YSR measure to have no more 
than eight problem items missing, as recommended by the measure's developers (Achenbach \& Rescorla, 2001). Two participants were excluded due to having more than eight missing YSR items, yielding a final sample size of 331 youths. We computed CBCL scales only if the CBCL also had eight or fewer missing items.

Information on the total number of diagnoses in our sample appears in Table 1 . Youth ages ranged from 7 to 14 years $(M=10.6, S D=1.7)$, and caregiver ages ranged from 21 to 78 $(M=41.2 ; S D=9.7)$. Youths from the two clinics generally did not differ ${ }^{1}$. Additional youth and primary caregiver demographic information appears in Table 2.

Measures

Child Behavior Checklist for Ages 6-18 (CBCL/6-18; Achenbach \& Rescorla, 2001). The 120 items on the CBCL are rated as Not True (0), Somewhat or Sometimes True (1), or Very True or often True (2). Validity and reliability of the narrow band (syndrome and DSM-oriented) and broad band (internalizing and externalizing) scale scores have been documented (Achenbach et al., 2001), and extensive normative data are available for children ranging from 6 to 18. We used raw CBCL scale scores for all analyses. Children's Interview for Psychiatric Syndromes, Child Version (ChIPS; Fristad et al., 1998; Teare et al., 1998). The ChIPS is 
a semi-structured interview designed to be administered to youth ages 6-18 years old. The interview screen for 20 different Axis I disorders and are based on the DSM-IV classification criteria. Content and concurrent validity, and inter-rater agreement of the ChIPS have been demonstrated in previous studies in clinical and community samples (e.g., Fristad et al., 1998; Teare et al., $1998)$.

Youth Self-Report (YSR; Achenbach \& Rescorla, 2001). The YSR is a self-report questionnaire developed to assess problems in youth ages 11-18. The 119 items on the YSR are rated as Not True (0), Somewhat or Sometimes True (1), or Very True or often True (2). The YSR developers intended it to be completed by youth with a mental age of 10 and fifth-grade reading skills (Achenbach \& Rescorla, 2001)². Validity and reliability of the YSR broad-band, syndrome and DSM-oriented scales have been documented (Achenbach \& Rescorla, 2001), and extensive normative data are available for children ages 11 to 18 . We used raw scores for all analyses.

Procedure

Legal guardians of all participating youths underwent standardized Institutional Review Board-approved notice of privacy and consent procedures prior to any data collection. Following consent provided at the initial meeting with the 
youths and their caretakers, the youths and caregivers filled out questionnaires including the YSR and CBCL. Youths also participated in the ChIPS structured interview conducted by assessors who were clinical psychology doctoral students and bachelor-level trained staff $^{3}$. Assessors were blind to the YSR and CBCL scores while formulating diagnoses.

Data preparation. Although missing data levels were low in our sample $(80.5 \%$ and $81.6 \%$ of the 331 participants had no missing YSR and CBCL items, respectively; and $12.3 \%$ and $12.7 \%$ had only 1 missing YSR and CBCL item, respectively), missing data were handled using the Missing Value Analysis (MVA) module of SPSS $15.0\left(\right.$ SPSS, 2006) ${ }^{4}$. To help ensure that all YSR and CBCL subscales were valid, we calculated each subscale only if it had less than 20\% missing items (cf. Ebesutani et al., 2010). Data Analytic Approach

Confirmatory factor analysis. We explored the model fit of the YSR narrow and broad band scales using both younger and older subsamples. We conducted confirmatory factor analysis (CFA), using LISREL 8.8. We used the Comparative Fit Index (CFI; Bentler, 1990) and the Root Mean Square Error of Approximation (RMSEA; Steiger, 1990) statistics to evaluate model fit. CFI 
values of .90 or greater (Bentler, 1990) and RMSEA values of .08 or lower (Browne \& Cudeck, 1993) suggest good model fit.

We then conducted a multi-sample CFA to assess the degree to which the DSM-oriented scales are invariant across younger and older youths with respect to factor form and other related model parameters (i.e., factor loadings, factor correlations, error variance) .

Scale reliability. We evaluated the reliability of the younger and older youths' reports on each of the YSR scales through estimating internal consistency via Cronbach's alpha coefficients. We used the .80 as the cut-off for acceptable reliability, as recommended by Nunnally and Bernstein (1994) for scale scores intended for use in clinical settings. Differences in internal consistency between groups were evaluated via Ftests for Cronbach's alphas from independent samples (Feldt, 1969; Feldt, Woodruff, \& Salih, 1987), adjusting the p-value criterion to $<.003(.05 / 17)$ to control for Type-1 error rates. As a basis for comparison, we also computed Cronbach's alpha coefficients for the narrow and broad band CBCL scales among the younger and older groups.

Concurrent validity. We used ANOVA and receiver operating characteristic (ROC) analyses to examine the degree of correspondence of younger youths' reports on the DSM-oriented scales with related DSM diagnoses. For the ROC analyses, Area 
Under the Curve (AUC) values indicate the degree to which an indicator predicts binary classification status (e.g., presence/absence of a diagnosis). AUC values may be interpreted as follows: AUC of .50-.70, poor;.70-.80, fair;.80-.90, good; .90-1.00, excellent (cf. Ferdinand, 2008). We also compared the relative performance of the younger and older youths' reports via z-test comparisons of AUC values (p-value criterion adjusted to $<.003(.05 / 16)$ to control for Type-1 error rates).

Correlational analyses. Lastly, we examined parent-child agreement ${ }^{5}$ of the younger youths compared to older youths. We used Fisher's z-tests to examine differences in (independent) correlations between groups (p-value criterion adjusted to $<.003(.05 / 16)$ to control for Type-1 error rates). To determine significance of individual correlations, we used the significance level of $p<.01$.

\section{Results and Discussion}

Factor Structure across Younger and older Youths

Adequate model fit was demonstrated among the younger and older samples for the 6-factor DSM-oriented scales (younger: RMSEA $=.068, \mathrm{CFI}=.87$; older: $\mathrm{RMSEA}=.070, \mathrm{CEI}=.87$ ), and the 8-factor syndrome scales (younger: RMSEA $=.077, \mathrm{CFI}=.80$; older: RMSEA $=.070, \mathrm{CFI}=.74)$. The multi-sample CFA solution 
evidenced support for "equal form" of the 6-factor DSM-oriented problems model across younger and older groups (i.e., RMSEA multisample $=.069)$. Further, allowing correlations between factors to be freely estimated did not significantly improve fit compared to specifying all factor correlation pairs to be equal across younger and older groups $\left[\chi^{2}\right.$ freely estimated model $(260)=4809.91$; $\chi^{2}$ constrained model $(2641)=4845.82 ; \chi^{2}$ difference $\left.(21)=35.91, p>.01\right]$ suggesting that the correlations between factors are generally equal across groups. Overall, the YSR scales evidenced supportive factorial validity across both younger and older youths.

Internal Consistency across Younger and older Youths

The Cronbach alpha values associated with reports on the YSR and CBCL specific to younger and older youths appear in Table 3 and Table 4, respectively. Results revealed that the YSR narrow band scales did not achieve adequate levels of reliability $(\alpha<.80)$ among the younger group, while the older group performed much better with respect to this benchmark. The younger youths' YSR broad band internalizing and externalizing scale scores, however, did meet the benchmark for acceptable reliability $(\alpha=.88, \alpha=.88$, respectively), supporting the reliability of the broad band scale scores for application with younger youth in clinical settings. This is an important finding, particularly as Muris and colleagues' (2004) found that younger 
youths (ages 8-10) were not able to provide reliable reports on the SDQ scales, including the Total Difficulties scale (alpha $=.76)$.

Concurrent Validity

Anxiety Problems scale. As seen in Table 5, both younger and older youths' reports on the Anxiety Problems scale were able to discriminate anxious youths from non-anxious youths, as evidenced by significant F-tests and AUC values significantly greater than chance level (i.e., AUC > .50). However, AUC values for the younger group fell in the "poor" range, whereas the AUC values for the older group fell in the "fair" range. AUC values between groups did not significantly differ.

ADH Problems scale. As seen in Table 5, younger youths' reports on the ADH Problems scale were able to discriminate youths with ADHD diagnoses from youths without ADHD. AUC values for both the younger and older groups fell in the "fair" range and did not significantly differ.

Oppositional Problems scale. As seen in Table 5, younger youths' reports on the Oppositional Problems scale were able to discriminate youths with diagnoses of oppositional defiant disorder (ODD) from youths without ODD, as well as youths with any disruptive behavior diagnosis (i.e., ODD, Conduct Disorder (CD) or disruptive behavior disorder nos) from youths without any disruptive behavior diagnosis. AUC values for the younger 
group fell in the "fair" range and did not significantly differ from the older group.

Affective, Conduct, and Somatic Problems scales. Given that there were insufficient numbers of youths diagnosed with CD (younger, $n=7$; older, $n=26$ ), affective disorders younger, $n=22$; older, $\mathrm{n}=17$ ), and somatic disorders (total n=0), concurrent validity analyses were omitted for the corresponding scales. ${ }^{6}$ Parent-child Agreement across Younger and Older Youths Results of the parent-child agreement analyses across younger and older youths appear in Table 6 and revealed that younger youths' parent-child agreement correlation coefficients were non-significant $(p>.01)$ for nearly all internalizing scales, but significant for some externalizing scales. The older youths evidenced significant parent-child correlations on both internalizing and externalizing scales, although primarily among the externalizing scales. These results are consistent with previous findings that parent-child agreement is worse among younger youth (Grills et al., 2003) and is greater for externalizing problems (e.g., Christensen et al., 1992). It is worth noting however that the low reliability associated with the younger youths' reports likely attenuated their parent-child agreement correlation coefficients relative to the older youths. Implications for Research, Policy, and Practice 
Practitioners and researchers seeking empirically supported assessment tools for younger youth may administer and interpret the YSR broad band internalizing and externalizing scales. Caution should be exercised however if narrow band scores are interpreted (given the lower reliability evidenced in the present study). More research is needed to better understand the psychometric properties of the narrow band scales among younger samples -- particularly given that they evidenced promising results in other domains (i.e., factor structure, concurrent validity)

Several limitations to the current study should also be noted. First, reliability of the younger and older youths' scale scores were estimated via Cronbach alpha coefficients. The addition of test-retest data of both younger and older youths would have provided an additional statistic with which to estimate reliability. In addition, concurrent validity estimates may have been inflated due the concurrent validity analyses being based on the same informant (i.e., both the YSR and ChIPS diagnostic data were derived from youth reports only). Future studies should also investigate the degree to which these reliability and validity statistics differ among older adolescent samples. Normative data for younger youths should also ideally be gathered - 
particularly for the broad band scales - to further increase the clinical utility of the YSR scales.

Nevertheless, results from the present study offer initial support for administration and interpretation of the YSR broad band scales to younger youths, and provide practitioners and researchers with an additional evidence-based assessment instrument to assess younger youths' emotional and behavioral problems. Given that YSR was designed to be completed by youth with fifth-grade reading skills, practitioners and researchers administering the YSR to younger youths should be prepared to provide assistance to children who have difficulty understanding items. The ASEBA manual (Achenbach et al., 2001) has reported guidelines for "respondents who cannot complete forms independently" (p.6), indicating that interviewers may read the questions to youths and record their responses for them. 
References

Achenbach, T., McConaughy, S., \& Howell, C. (1987). Child/ adolescent behavioral and emotional problems:Implications of cross-informant correlations for situational specificity. Psychological Bulletin, 11, 213-232.

Achenbach, T. \& Rescorla, L. (2001). The Manual for the ASEBA School-Age Forms \& Profiles. Burlington, VT: University of VT, Research Center for Children, Youth, and Families. Bentler, P. (1990). Comparative fit indices in structural models. Psychological Bulletin, 107, 238-246.

Browne, M. \& Cudeck, R. (1993). Alternative ways of assessing model fit. In K. Bollen \& J. Long (Eds.), Testing structural equation models (pp.136-162). Newbury Park, CA: Sage.

Christensen, A., Margolin, G., \& Sullaway, M. (1992). Interparental Agreement on Child Behavior Problems, Psychological Assessment, 4, 419-425.

Ebesutani, C., Bernstein, A., Nakamura, B., Chorpita, B., \& Weisz, J. (2010). A psychometric analysis of the Revised Child Anxiety and Depression Scale - parent version in a clinical sample. Journal of Abnormal Child Psychology, 38, $249-260$.

Edelbrock, C., Costello, A. Dulcan, M., Conover, N, \& Kalas, R. (1986). Parent-child agreement on child psychiatric symptoms assessed via structured interview. Journal of Child 
Psychology and Psychiatry, 27, 181-190.

Feldt, L. S. (1969). A test of the hypothesis that Cronbach's alpha or Kuder-Richardson coefficient twenty is the same for two tests. Psychometrika, 34, 363- 373.

Feldt, L. S., Woodruff, D. J., \& Salih, F. A. (1987).

Statistical inference for coefficient alpha. Applied Psychological Measurement, 11, 93-103.

Ferdinand, R. (2008). Validity of the CBCL/YSR DSM-IV scales anxiety problems and affective problems. Journal of Anxiety Disorders, 22, 126-134.

Flesch R. (1951). How to test readability. New York: Harper \& Brothers.

Fristad, M. A., Cummins, J., Verducci, J. S., Teare, M., Weller, E. B., \& Weller, R. A. (1998). Study V: Children's Interview for Psychiatric Syndromes (ChIPS) psychometrics in two community samples. Journal of Child and Adolescent Psychopharmacology, 8, 237-245.

Grills, A. E., \& Ollendick, T. H. (2003). Multiple informant agreement and the anxiety disorders interview schedule for parents and children. Journal of the American Academy of Child \& Adolescent Psychiatry, 42, 30-40.

Kolko, D., \& Kazdin, A. (1991). Motives of childhood firesetters: Firesetting characteristics and psychological correlates. Journal of Clinical Child \& Adolescent 
Psychology, 32, 535-550.

Kolko, D., \& Kazdin, A. (1993). Emotional/behavioral problems in clinic and nonclinic children: Correspondence among child, parent and teacher reports. Journal of Child Psychology and Psychiatry, 34, 991-1006.

McCarthy, C. \& Weisz, J. R. (2002). Correlates of expressed emotion in mothers of clinically-referred youth: an examination of the five-minute speech sample. Journal of Child Psychology and Psychiatry, 43(6), 759-768.

Meyer, G., Finn, S., Eyde, L., Kay, G., Moreland, K., Dies, R., Eisman, E., et al. (2001). Psychological testing and psychological assessment: A review of evidence and issues. American Psychologist, 56, 128-165.

Muris, P., Meesters, C., Eijkelenboom A., \& Vincken, M. (2004). The self-report version of the Strengths and Difficulties Questionnaire: Its psychometric properties in 8- to 13-yearold non-clinical children. British Journal of Clinical Psychology, 43, 437-448.

Nunnally, J. \& Bernstein, I. (1994). Psychometric Theory (3rd ed). New York: McGraw-Hill.

SPSS, Inc. (2006). S.P.S.S. 15.0 Base User's Guide: Prentice Hall.

Steiger, J. H. (1990). Structural model evaluation and modification: An interval estimation approach. Multivariate 
Behavioral Research, 25, 173-180.

Teare, M., Fristad, M. A., Weller, E. B., Weller, R. A., \&

Salmon, P. (1998). Study II: concurrent validity of the DSMIII-R Children's Interview for Psychiatric Syndromes (ChIPS). Journal of Child and Adolescent Psychopharmacology, 8, 213219.

Treutler, C., \& Epkins, C. (2003). Are discrepancies among child, mother, and father reports on children's behavior related to parents' psychological symptoms and aspects of parent-child relationships? Journal of Abnormal Child Psychology, 31, 13-27.

Vreugdenhil, C., van den Brink, W., Ferdinand, R., Wouters, L., \& Doreleijers, T. (2006). The ability of YSR scales to predict DSM/DISC-C psychiatric disorders among incarcerated male adolescents. European Child \& Adolescent Psychiatry, 15, $88-96$.

Yeh, M., \& Weisz, J. (2001). Why are we here at the clinic? Parent-child (dis) agreement on referral programs at outpatient treatment entry. Journal of Consulting and Clinical Psychology, 69, 1018-1025. 


\section{Footnotes}

1. Youths from the two clinics did not differ with respect to youth age (Hawaii: mean age $=10.55$, S.D. $=1.77$; Boston: mean age $=10.76$, S.D. $=1.70), p=.30$, parent age (Hawaii: mean age $=42.04$, S.D. $=9.94 ;$ Boston: mean age $=40.84$, S.D. $=9.65), p=.31$, and mean number of comorbid diagnoses (Hawaii: mean $=1.32, S . D .=1.15 ;$ Boston: mean $=$ 1.08, S.D. $=1.35), p=.12$. However, a significant difference in gender ratio was found between clinics (Hawaii: 75\% male; Boston 62\% male), $p<.01$. With respect to differences in scale scores between the two clinics, youths from the two clinics did not differ significantly on the CBCL Externalizing scale (Hawaii: mean = 15.4, S.D. = 9.8; Boston: mean $=17.0$, S.D. $=10.8), p=.20, \mathrm{CBCL}$ Internalizing scale (Hawaii: mean $=14.8$, S.D. $=9.6$; Boston: mean $=16.9$, S.D. $=9.6), p=.06$, or the YSR Externalizing scale (Hawaii: mean $=11.8$, S.D. $=9.4$; Boston: mean $=9.5, S . D .=7.6), p=.02$. Youths did differ however on the YSR Internalizing scale (Hawail: mean $=16.2$, S.D. $=10.5 ;$ Boston: mean $=13.0$, S.D. $=8.6), p<.01$.

2. Although the YSR developers intended the YSR to be completed by youth with a mental age of 10 and fifth-grade reading skills, analysis of the YSR items via the FleschKincaid readability scale (Flesch, 1951) yielded a Flesch 
Reading Ease score of 100.0, and a Flesch-Kincaid Grade Level score $=0.6$. Flesch Reading Ease scores of 90-100 indicate easily understandable items for an average 11year-old student, and the Flesch-Kincaid Grade Level score corresponds to grade reading level. These results thus indicate that the YSR items are highly readable, even among children under 11 years old.

3. Although inter-rater reliability data of these structured interviews were not gathered, assessors in the present study were trained to reliability using the ChIPS. Becoming trained to reliability involved (a) observation of three ChIPS interviews conducted by trained assessors, (b) conducting a series of five ChIPS interviews while being observed by a criterion-trained assessor, (c) matching the experienced assessor on all clinical diagnoses in three of the five interviews and (d) matching the experienced interviewer on the Clinical severity Ratings (CSRS) within at least one point on all diagnoses given. CSRs are ratings provided by the assessor which range from 0-10 and indicate clinical severity of each disorder. CSRs $\geq 5$ indicate clinically significant severity for each disorder.

4. Notably, missing item values can be a sign that items were not understood by the respondent (e.g., the youth). We thus examined the number of missing items specific to the 
younger and older youths in the present study. The number of missing YSR items for both the younger and older groups were low. Specifically, the percentage of younger and older youths with missing YSR items were as follows: 0 missing YSR items - 80\% and 85\%, respectively; 1 missing item - 13\% and $11 \%$, respectively; 2 missing items: 3\% and 1\%, respectively; 3-8 missing items: 4\% and 3\%, respectively). Both younger and older youths thus had comparable (low) levels of missing data.

5. As some CBCL DSM-oriented, syndrome, and broad-band scales contain additional items not present on the YSR (i.e., the CBCL DSM-oriented Conduct Problem scale includes two more items than the YSR DSM-oriented Conduct Problem scale; the CBCL internalizing scale includes one more item than the YSR internalizing scale; the CBCL externalizing scale includes three more items than the YSR externalizing scale; five of the eight CBCL syndrome scales include 1-3 more items than the corresponding YSR syndrome scales), we rescored these CBCL scales excluding the non-overlapping items. We then used these re-scored CBCL scales (based on YSR/CBCL overlapping items only) in the correlational analyses, so as to eliminate bias towards lower correspondence due to the additional CBCL items. 
6. Despite having insufficient power for these analyses, we conducted these analyses on the younger and older subsamples for illustrative purposes. The 7 younger youths with CD scored higher on the DSM-oriented Conduct Problems scale $($ mean $=9.43$, S.D. $=3.87)$ than the 174 younger youths without $\mathrm{CD}$ (mean $=2.67, \mathrm{~S} . \mathrm{D} .=3.32), \mathrm{F}=28.97, \mathrm{p}$ $<.001$. The 26 older youths with CD also scored higher on the DSM-oriented Conduct Problems scale (mean $=9.17$, S.D. $=4.50)$ than the 119 older youths without $\mathrm{CD}$ (mean $=3.40$, S.D. $=3.08), F=62.51, p<.001$. With respect to the DSMoriented Affective Problems scale, the 22 younger youths with any affective disorder (i.e., major depressive disorder, dysthymic disorder, mood disorder not otherwise specified) scored higher on this scale (mean $=7.77, \mathrm{~S} . \mathrm{D} .=$ 3.46) than the 159 younger youths without affective disorders $($ mean $=5.24, \mathrm{~S} . \mathrm{D} .=3.89), \mathrm{F}=8.44, p=.004$. The 17 older youths with any affective disorder also scored higher on the DSM-oriented Affective Problems scale (mean = 7.65, S.D. $=2.96)$ than the 129 older youths without affective disorders (mean $=4.27$, S.D. $=4.07), F=10.95$, $p=.001$. 
Table 1

Number of Diagnoses anywhere and primary in youths' diagnostic profile (N=331)

\begin{tabular}{|c|c|c|c|c|c|c|}
\hline \multirow{3}{*}{ Diagnoses } & \multicolumn{6}{|c|}{ Specifier } \\
\hline & \multicolumn{3}{|c|}{ Primary } & \multicolumn{3}{|c|}{ Anywhere } \\
\hline & Total & Young & Older & Total & Young & Older \\
\hline Anxiety Disorders & 71 & 49 & 22 & 134 & 91 & 43 \\
\hline Generalized anxiety disorder & 6 & 3 & 3 & 16 & 10 & 6 \\
\hline Separation anxiety disorder & 25 & 21 & 4 & 45 & 36 & 9 \\
\hline Specific Phobia & 22 & 15 & 7 & 39 & 25 & 14 \\
\hline Social phobia & 10 & 2 & 8 & 16 & 6 & 10 \\
\hline Obsessive-compulsive disorder & 4 & 4 & 0 & 10 & 8 & 2 \\
\hline PTSD & 2 & 2 & 0 & 4 & 3 & 1 \\
\hline Panic Disorder & 0 & 0 & 0 & 0 & 0 & 0 \\
\hline Anxiety NOS & 2 & 2 & 0 & 4 & 3 & 1 \\
\hline Affective Disorders & 17 & 8 & 9 & 38 & 21 & 17 \\
\hline Major depressive disorder & 11 & 4 & 7 & 25 & 12 & 13 \\
\hline Dysthymic disorder & 4 & 2 & 2 & 8 & 5 & 3 \\
\hline Depressive Disorder NOS & 2 & 2 & 0 & 5 & 4 & 1 \\
\hline ADHD Disorders & 30 & 13 & 17 & 82 & 48 & 34 \\
\hline ADHD-Combined & 5 & 3 & 2 & 24 & 19 & 5 \\
\hline ADHD- Predominantly Inattentive & 13 & 4 & 9 & 32 & 14 & 18 \\
\hline ADHD-Predominantly Hyperactive & 0 & 0 & 0 & 2 & 1 & 1 \\
\hline ADHD-NOS & 12 & 6 & 6 & 24 & 14 & 10 \\
\hline Disruptive Behavior Disorders & 70 & 32 & 38 & 115 & 58 & 57 \\
\hline Oppositional defiant disorder & 53 & 28 & 25 & 81 & 50 & 31 \\
\hline Conduct disorder & 17 & 4 & 13 & 33 & 7 & 26 \\
\hline Disruptive behavior disorder NOS & 0 & 0 & 0 & 1 & 1 & 0 \\
\hline Bipolar & 1 & 1 & 0 & 1 & 1 & 0 \\
\hline Schizophrenia & 2 & 2 & 0 & 3 & 3 & 0 \\
\hline PDD & 0 & 0 & 0 & 0 & 0 & 0 \\
\hline Other & 3 & 2 & 1 & 6 & 2 & 4 \\
\hline \multirow{2}{*}{ No Diagnosis } & 133 & 74 & 59 & 133 & 74 & 59 \\
\hline & & & & \multicolumn{3}{|c|}{ Comorbidity } \\
\hline Comorbidity & & & & Total & Young & Older \\
\hline Single Diagnosis & & & & 82 & 39 & 43 \\
\hline Two Comorbid Diagnoses & & & & 70 & 39 & 31 \\
\hline Three Comorbid Diagnoses & & & & 22 & 16 & 6 \\
\hline Four Comorbid Diagnoses & & & & 10 & 6 & 4 \\
\hline Five Comorbid Diagnoses & & & & 9 & 6 & 3 \\
\hline Six Comorbid Diagnosis & & & & 1 & 1 & 0 \\
\hline
\end{tabular}

Note. $\mathbf{A D H D}=$ Attention-Deficit/Hyperactivity Disorder; Anywhere $=$ a diagnosis that appears anywhere in a child's diagnostic profile; "Other" includes substance abuse, substance dependence, enuresis, trichotillomania. $\mathbf{P D D}=$ Pervasive Developmental Disorder; Primary $=\mathrm{a}$ 
child's primary diagnosis; PTSD = post traumatic stress disorder. Diagnostic data were missing for three younger youths and one older youth. Therefore, the total number of primary disorders (including no diagnosis) does not sum to the total sample size of 331. 
Table 2

Youth and Caregiver Demographic Information

\begin{tabular}{|c|c|c|}
\hline & $n$ & Percentage \\
\hline \multicolumn{3}{|l|}{ Youth Gender } \\
\hline Boys & 218 & 65.9 \\
\hline Girls & 113 & 34.1 \\
\hline \multicolumn{3}{|l|}{ Youth Ethnicity } \\
\hline Multiethnic & 96 & 29.0 \\
\hline White & 155 & 46.8 \\
\hline African American & 33 & 10.0 \\
\hline Asian American & 11 & 3.3 \\
\hline Latino/Hispanic & 25 & 7.6 \\
\hline Other & 9 & 2.7 \\
\hline Missing & 2 & 0.6 \\
\hline \multicolumn{3}{|l|}{ Caregiver Type } \\
\hline Biological Mother & 192 & 58.0 \\
\hline Biological Father & 63 & 19.0 \\
\hline Adoptive Mother & 8 & 2.4 \\
\hline Adoptive Father & 6 & 1.8 \\
\hline Grandmother & 17 & 5.1 \\
\hline Grandfather & 10 & 3.0 \\
\hline Other & 22 & 6.6 \\
\hline Missing & 13 & 3.9 \\
\hline \multicolumn{3}{|l|}{ Caregiver Marital Status } \\
\hline Married & 129 & 39.0 \\
\hline Divorced, separated & 99 & 29.9 \\
\hline Widowed & 16 & 4.8 \\
\hline Single & 53 & 16.0 \\
\hline Missing & 34 & 10.3 \\
\hline \multicolumn{3}{|c|}{ Caregiver Highest Level of Education } \\
\hline No high school & 31 & 9.4 \\
\hline High school/GED & 102 & 30.8 \\
\hline College & 169 & 51.1 \\
\hline Graduate School & 22 & 6.6 \\
\hline Missing & 7 & 2.1 \\
\hline \multicolumn{3}{|l|}{ Family Income } \\
\hline$\$ 0-\$ 39,000$ & 182 & 55.0 \\
\hline$\$ 40,000-\$ 79,000$ & 82 & 24.8 \\
\hline$\$ 80,000-\$ 119,000$ & 34 & 10.3 \\
\hline$\$ 120,000$ or more & 17 & 5.1 \\
\hline Miccino & 16 & $\triangle 8$ \\
\hline
\end{tabular}


Table 3

YSR Internal Consistency Cronbach Alpha for Younger $(N=184)$ and Older $(N=147)$ Subsamples

\begin{tabular}{|c|c|c|c|c|}
\hline \multirow[b]{2}{*}{ Youth Self Report } & \multicolumn{2}{|c|}{$\begin{array}{c}\text { Subsample } \\
\text { Cronbach Alpha }\end{array}$} & \multicolumn{2}{|c|}{$\begin{array}{c}\text { Cronbach } \\
\text { Difference } F \text {-tests }\end{array}$} \\
\hline & Younger & Older & $\chi^{2}$ value & $p$ \\
\hline \multicolumn{5}{|l|}{ DSM-oriented scales } \\
\hline Affective Problems & .68 & .79 & 5.45 & .02 \\
\hline Anxiety Problems & .61 & .70 & 1.81 & .18 \\
\hline Somatic Problems & .78 & .76 & 0.48 & .49 \\
\hline ADH Problems & .78 & .78 & 0.00 & .96 \\
\hline Oppositional Problems & .70 & .76 & 1.37 & .24 \\
\hline Conduct Problems & .77 & .81 & 0.86 & .35 \\
\hline \multicolumn{5}{|l|}{ Syndrome scales } \\
\hline Anxious/Depressed & .75 & .83 & 4.19 & .04 \\
\hline Withdrawn/Depressed & .69 & .67 & 0.12 & .73 \\
\hline Somatic Complaints & .79 & .80 & 0.01 & .93 \\
\hline Social Problems & .75 & .74 & 0.01 & .92 \\
\hline Thought Problems & .75 & .74 & 0.09 & .77 \\
\hline Attention Problems & .77 & .82 & 1.84 & .18 \\
\hline Rule-Breaking Behavior & .70 & .78 & 3.03 & .08 \\
\hline Aggressive Behavior & .85 & .85 & 0.08 & .78 \\
\hline \multicolumn{5}{|l|}{ Broad-band scales } \\
\hline Internalizing & .88 & .89 & 0.47 & .49 \\
\hline Externalizing & .88 & .89 & 0.65 & .42 \\
\hline Total & .93 & .93 & 0.00 & 1.00 \\
\hline
\end{tabular}

Note. ADH Problems = Attention Deficit/Hyperactivity Problems. 
Table 4

CBCL Internal Consistency Cronbach Alpha for Younger $(N=184)$ and Older $(N=147)$ Subsamples

\begin{tabular}{|c|c|c|c|c|}
\hline \multirow[b]{2}{*}{ Child Behavior Checklist } & \multicolumn{2}{|c|}{$\begin{array}{c}\text { Subsample } \\
\text { Cronbach Alpha }\end{array}$} & \multicolumn{2}{|c|}{$\begin{array}{c}\text { Cronbach } \\
\text { Difference } F \text {-tests }\end{array}$} \\
\hline & Younger & Older & $\chi^{2}$ value & $p$ \\
\hline \multicolumn{5}{|l|}{ DSM-oriented scales } \\
\hline Affective Problems & .77 & .77 & 0.00 & 1.00 \\
\hline Anxiety Problems & .74 & .74 & 0.00 & 1.00 \\
\hline Somatic Problems & .76 & .67 & 2.96 & .09 \\
\hline ADH Problems & .83 & .81 & 0.38 & .54 \\
\hline Oppositional Problems & .80 & .81 & 0.07 & .79 \\
\hline Conduct Problems & .86 & .85 & 0.17 & .68 \\
\hline \multicolumn{5}{|l|}{ Syndrome scales } \\
\hline Anxious/Depressed & .80 & .86 & 4.34 & .04 \\
\hline Withdrawn/Depressed & .75 & .80 & 1.55 & .21 \\
\hline Somatic Complaints & .79 & .69 & 5.07 & .02 \\
\hline Social Problems & .78 & .76 & 0.26 & .61 \\
\hline Thought Problems & .75 & .69 & 1.60 & .21 \\
\hline Attention Problems & .85 & .83 & 0.51 & .48 \\
\hline Rule-Breaking Behavior & .73 & .75 & 0.21 & .65 \\
\hline Aggressive Behavior & .90 & .90 & 0.00 & 1.00 \\
\hline \multicolumn{5}{|l|}{ Broad-band scales } \\
\hline Internalizing & .88 & .89 & 0.29 & .59 \\
\hline Externalizing & .91 & .92 & 0.53 & .47 \\
\hline Total Problems & .92 & .92 & 0.00 & 1.00 \\
\hline
\end{tabular}

Note. ADH Problems $=$ Attention Deficit/Hyperactivity Problem 
IR DSM-oriented Anxiety, ADH, and Oppositional Problems scale Means and ROC Area Under the Curve (AUC) Values $f$ unger (ages 7-10) and Older (ages 11-14) Youths with and without Related Diagnoses Anywhere in Their Diagnostic Prof

\begin{tabular}{|c|c|c|c|c|c|c|c|c|c|}
\hline \multirow{2}{*}{ sle } & \multirow{2}{*}{$D S M$ scale } & \multirow{2}{*}{ Diagnostic Groups } & \multicolumn{4}{|c|}{ ANOVA } & \multicolumn{3}{|c|}{ ROC } \\
\hline & & & $n$ & $M(S D)$ & $F$ & $p$ & AUC & $\mathrm{SE}$ & $z$ \\
\hline \multirow[t]{2}{*}{ Iger } & Anxiety & SAD/GAD/SPEC & 55 & $4.16(2.59)$ & & & & & \\
\hline & & No SAD/GAD/SPEC & 126 & $2.55(2.10)$ & 19.50 & $<.003$ & .68 & .045 & \\
\hline \multirow[t]{2}{*}{$\mathrm{r}$} & Anxiety & $\mathrm{SAD} / \mathrm{GAD} / \mathrm{SPEC}$ & 23 & $4.83(2.42)$ & & & & & \\
\hline & & No SAD/GAD/SPEC & 123 & $2.50(2.23)$ & 20.53 & $<.003$ & .77 & .050 & 1.34 \\
\hline \multirow[t]{2}{*}{ Iger } & Anxiety & Any Anxiety & 65 & $4.05(2.47)$ & & & & & \\
\hline & & No Anxiety & 116 & $2.48(2.12)$ & 20.12 & $<.003$ & .69 & .041 & \\
\hline \multirow[t]{2}{*}{$\mathrm{r}$} & Anxiety & Any Anxiety & 30 & $5.00(2.53)$ & & & & & \\
\hline & & No Anxiety & 116 & $2.31(2.05)$ & 37.01 & $<.003$ & .80 & .047 & 1.76 \\
\hline \multirow[t]{2}{*}{ iger } & $\mathrm{ADH}$ & ADHD-PI/PH/C & 34 & $7.11(3.09)$ & & & & & \\
\hline & & No ADHD-PI/PH/C & 147 & $4.40(3.40)$ & 18.17 & $<.003$ & .72 & .042 & \\
\hline \multirow[t]{2}{*}{ r } & $\mathrm{ADH}$ & ADHD-PI/PH/C & 24 & $7.45(2.76)$ & & & & & \\
\hline & & No ADHD-PI/PH/C & 122 & $5.26(3.30)$ & 9.28 & .003 & .70 & .055 & 0.29 \\
\hline \multirow[t]{2}{*}{ iger } & $\mathrm{ADH}$ & Any ADHD & 48 & $7.14(2.94)$ & & & & & \\
\hline & & No ADHD & 133 & $4.10(3.34)$ & 31.01 & $<.003$ & .75 & .037 & \\
\hline \multirow[t]{2}{*}{$\mathrm{r}$} & $\mathrm{ADH}$ & Any ADHD & 34 & $7.61(2.46)$ & & & & & \\
\hline & & No ADHD & 112 & $5.02(3.31)$ & 17.89 & $<.003$ & .74 & .044 & 0.17 \\
\hline \multirow[t]{2}{*}{ iger } & Oppositional & ODD & 50 & $3.80(2.17)$ & & & & & \\
\hline & & No ODD & 131 & $1.90(1.97)$ & 31.97 & $<.003$ & .75 & .039 & \\
\hline \multirow[t]{2}{*}{$\mathrm{r}$} & Oppositional & ODD & 31 & $4.97(2.11)$ & & & & & \\
\hline & & No ODD & 115 & $3.00(2.30)$ & 18.61 & $<.003$ & .73 & .047 & 0.33 \\
\hline \multirow[t]{2}{*}{ iger } & Oppositional & Any Disruptive & 58 & $3.96(2.29)$ & & & & & \\
\hline & & No Disruptive & 123 & $1.70(1.73)$ & 54.38 & $<.003$ & .79 & .035 & \\
\hline \multirow[t]{2}{*}{$\mathrm{r}$} & Oppositional & Any Disruptive & 57 & $5.02(2.18)$ & & & & & \\
\hline & & No Disruptive & 89 & $2.39(1.92)$ & 58.70 & $<.003$ & .81 & .037 & 0.39 \\
\hline
\end{tabular}


SAD/GAD/SPEC = youths with separation anxiety disorder, generalized anxiety disorder; and/or specific phobia; Any Al hs with separation anxiety disorder, generalized anxiety disorder, specific phobia, obsessive-compulsive disorder, post atic stress disorder, panic disorder, social phobia, and/or anxiety disorder not otherwise specified; $\mathbf{A D H D}-\mathbf{P I} / \mathbf{P H} / \mathbf{C}=$ yout IDHD-PI, ADHD-PH, or ADHD-C; Any ADHD = youths with ADHD-PI, ADHD-PH, ADHD-C, or ADHD-NOS; ODD itional defiant disorder; Any Disruptive = youths with oppositional defiant disorder, conduct disorder, or disruptive behav er not otherwise specified; * All AUC values were significantly greater than $.50, p<.001$. 
Table 6

Parent-child Agreement between Corresponding YSR and CBCL Scales for Both Younger (ages 7-10) and Older (ages 11-14) Subsamples

\begin{tabular}{|c|c|c|c|}
\hline \multirow{2}{*}{ YSR and CBCL scales } & \multicolumn{2}{|c|}{ Correlations } & \multirow{2}{*}{$\frac{\text { Fisher's } z \text {-test }}{z}$} \\
\hline & Younger (n) & Older (n) & \\
\hline \multicolumn{4}{|l|}{ DSM-Oriented } \\
\hline Affective Problems & $.140(184)$ & $.225 * *(146)$ & 0.79 \\
\hline Anxiety Problems & $.160 *(183)$ & $.360 * *(145)$ & $1.92 *$ \\
\hline Somatic Problems & $.162 *(183)$ & $.219 * *(145)$ & 0.53 \\
\hline ADH Problems & $.047(184)$ & $.404 * *(146)$ & $3.41 * * *$ \\
\hline Oppositional Problems & $.216 * *(184)$ & $.425 * *(146)$ & $2.09 *$ \\
\hline Conduct Problems & $.246 * *(184)$ & $.614 * *(145)$ & $4.14 * * *$ \\
\hline \multicolumn{4}{|l|}{ Syndrome } \\
\hline Anxious/Depressed & $.167 *(184)$ & $.282 * *(145)$ & 1.08 \\
\hline Withdrawn/Depressed & $.008(183)$ & $.159(146)$ & 1.36 \\
\hline Somatic Problems & $.126(183)$ & $.170 *(145)$ & 0.40 \\
\hline Social Problems & $.197 * *(184)$ & $.283(146)$ & 0.82 \\
\hline Thought Problems & $.097(184)$ & $.042(146)$ & 0.49 \\
\hline Attention Problems & $.084(184)$ & $.352 * *(146)$ & $2.53 * *$ \\
\hline Rule-Breaking & $.162 *(184)$ & $.536 * *(145)$ & $3.88 * * *$ \\
\hline Aggressive Behavior & $.231 * *(184)$ & $.461 * *(146)$ & $2.35 * *$ \\
\hline \multicolumn{4}{|l|}{ Broad-band } \\
\hline Internalizing & $.059(184)$ & $215^{* *}(146)$ & 1.42 \\
\hline Externalizing & $.233 * *(184)$ & $.515 * *(146)$ & $2.97 * *$ \\
\hline
\end{tabular}

$* p<.05 . * * p<.01 . * * * p<.003$. 